\title{
SCIENCE
}

Friday, ApriL 5, 1918

CONTENTS

The American Association for the Advancement of Science:-

Geology in Education: Professor Rollin

D. SALISBURX

The Report of the Committee to visit the Harvard College Observatory ............. 335

Scientific Events:-

The Museum of the University of Pennsylvania; Reconstruction Commissions of the British Government; Meeting of the General Medical Board of the Council of $\mathrm{Na}$ tional Defense; Lectures on Agriculture.... 337

Scientific Notes and News ............. 340

University and Educational News 342

Discussion and Correspondence:-

Scott on the Canons of Comparative Anatomy: Professor E. C. Jefrrey. The Jerusalem Artichoke as a War Plant: DR. L. O. Howard. Poisoning Tree Parasites with Cyanide of Potassium: Professor Maynard M. Metcalf. Systematists and General Biologists: Dr. F. A. BATHER ... 343

Scientific Booles:-

Lectures on Heredity: Professor G. N.

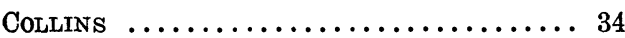

Special Articles:-

The Rôle of Catalase in Acidosis: Dr. W.

E. BURGE $\ldots \ldots \ldots \ldots \ldots \ldots \ldots \ldots \ldots, 347$

MSS. intended for publication and books, etc., intended for review should be sent to 'The Editor of Science, Garrison-onHudson, N. Y.

\section{GEOLOGY IN EDUCATION 1}

WHAT would be the result if those who are interested in education could come de novo to the question of the content of an ideal curriculum of study? It probably is safe to say that one of the results would be a shock to those whose opinions on this matter have been shaped by the prejudices which accompany our inheritance. That evolution is a slow process is illustrated nowhere better than in educational circles.

Let it be assumed that the consideration of what is most valuable in education could be approached by a jury which has an intelligent grasp of all subjects, as now understood, and of these subjects in their proper relations. Let it be assumed further that the jury is unprejudiced by tradition or by pronounced personal bents in favor of or against individual subjects. What conclusions would they reach? To this question there is of course no categorical answer. Wisdom would decree that there is no one model curriculum-that there should be various types of curricula, each susceptible of adaptation to individual needs.

The classes of subjects whose claims would need to be considered in such a study as that here suggested fall into several general classes. It goes without saying that their values would be differently gauged by different men, and that their values are different for different men.

Without presuming to make an exhaustive classification, it is clear that one great

1 Address of the vice-president and chairman of Section E-Geology and Geography-American Association for the Advancement of Science, Pittsburgh, December, 1917. 
group of subjects deals with men, what they have thought and what they have done, how they have moved on from one mode of thinking and doing, to other modes of thinking and doing. In the evolution of education, it came about that great importance was attached to the languages in which people recorded what they thought and did; but if we could come to this question anew, with all modern facilities for getting the things which are recorded in one language into available form in another, it is not clear that languages which are no longer in use would be regarded as vitally important for the average student. If it is important to know what was thought and done in the past, as it doubtless is, there must be scholars who command the languages in which ancient thought and ancient history are recorded. They should be our interpreters, who put into modern language the valuable part of that which is recorded in languages which are no longer spoken.

I suppose no more conspicuous example of intellectual waste can be pointed to in all the history of our unintelligent educational development than the waste of time on languages which no longer live. The stock argument that the study of these languages is helpful in the use of our own, is an argument for waste. If half the time were devoted to English, which is put upon Latin for the sake of helping English, the average student probably would advance much farther in the use of his own tongue.

What the people of long ago thought and did is of importance chiefly in its bearing on modern life. This bearing should not be belittled, and is a sufficient warrant for the study of ancient history, and of the philosophies and literatures from which our modern philosophies and literatures are descended. Yet it is easy to exaggerate the importance of even these things. Some one has told us that "history is always interesting, but rarely instructive." Such epigrams, and this one is as true as most, warn us of the futility of depending too much on the past for guidance. While history helps us in some measure to understand what is happening in the present world-crisis, yet all history, ancient and modern, plays a trivial part as compared with geography, chemistry and physics, in explanation of the course of the present war. History will in the end be invaluable in the interpretation of the war, but its importance in the crisis is slight. The dictum that history repeats itself can hardly be taken literally, or even very seriously. If it does, it repeats with variations so extraordinary that they are more prominent than the theme which they accompany. Nevertheless, that which people have thought and done is likely to remain an important element in education, and it is perhaps the sociological and economic aspects of history which are of greatest moment.

In human affairs, the past is important chiefly as a setting for the present. It is the present in which we live and move and have our being, and it is the future for which we are planning. In so far as study of the past helps us in the present, it should be cultivated. Is there adequate basis for going farther, in the average case? I believe that the most serious criticism of the old curricula, some of which still persist, is the undue proportion of time given to the languages and events of times so distant that they have little bearing on the problems of the present.

There is another class of subjects which deals with the present, with facts and conditions of to-day, and with what people are now doing and thinking. Current thought, current political, social, and in- 
dustrial life, current processes in the utilization of resources, and progress in the development of principles which are to guide activities and affairs in the immediate future, these are the themes of this group of subjects. If we could free ourselves from the bias of tradition, can it be doubted that in a perfected outline of study these subjects would have a far larger place than they have had in the past, or than they have now in many institutions? Modem history, modern sociology, modern industrial life, modern economics, modern science in its application to human welfare, conservation-these are things which fit men and women for life in the present, and prepare the way for life in the future. In the successful prosecution of these studies, the languages in which the current record of their development is writ, are, of course, important.

Two years ago, I heard a Phi Beta Kappa man, just graduating from a large university, say that he felt absolutely out of touch with current affairs, that he knew far less about what people are thinking and doing, than he did when he entered college. That a normal man could make such a statement on completing a college course, seems to me a reproach to modern college education. Present-day thought, and present-day activities in connection with vital problems should, it seems to me, enter in a large way, into the curriculum of every normal student. And, for my part, I should be particular only that there be enough of the past to give a proper setting for the present, making provision always for the specialization of the exceptional student on any phase of any subject, at any stage of its evolution.

There is a third class of subjects which deals with facts and principles which have no necessary relation to historic time. The time element is involved, in many cases, in the development of facts and the evolution of principles, and in this connection it may be of vital importance. In many cases the history is interesting rather than instructive, but in others the bearing of principles and the significance of their application are revealed by their history, a history based on natural laws rather than on the caprices of men.

To this class belong most of the subjects popularly designated "science." The underlying principles are immutable, though their interpretation has changed from time to time, chiefly in the direction of completer understanding; and this change of interpretation is sure to go on, perhaps indefinitely. Once principles are established, further progress is by way of their development and enlarged application.

Most of these subjects involve an element of history which can not be ignored. There is the accumulated and accumulating body of fact on which interpretation is based. To the average student, the details of this history are not very vital, but to the specialist in any science they are vital, for in many cases facts are temporarily misinterpreted, partially interpreted, or even uninterpreted, for long periods of time. They must be stored until the time comes when they can be fitted into their proper places and their true significance grasped.

Geology belongs to this class of subjects, and among subjects of this class perhaps no one is better qualified to really educate the student.

In the first place, this is the earth we live on. It is the home of man, the only home of the only men that ever were or ever will be, so far as we now know. The past, the present, and the future of the human race, to the best of present knowledge, are bound up with it. They have been, are, and will be dependent on con- 
ditions which exist here. They are intimately connected with the resources which science has discovered and learned to use, for it is reasonably certain that our progress in this direction is not ended, and quite possible that it is only well begun. Progress in the utilization of earth resources involves the results of sciences other than geology-especially chemistry and physics.

It is of course known, but not widely realized, that a large proportion of the people of the earth gets its living from the utilization of the materials of geology. The workers of the soil are not only making use of geologic materials daily, but are dependent on them. The efficiency of soilworkers would, in the long run, be far greater, if they understood how soils come into existence and how they are lost, how they are exhausted and how their exhaustion may be prevented. To supply this knowledge to soil-workers would be to increase the products of their labor, to better their condition, and to feed the rest of the world more cheaply. Have we any right to withhold such knowledge from the youth who are to deal with the soil? It is true that they learn much empirically. It is true that agricultural colleges and the Federal Department of Agriculture are supplying much useful information to large numbers of men, young and old; it is true that almost any man can gain needed information of a practical sort on these subjects, if he is well enough informed to know what he needs, and how to get it.

But in spite of state and federal efforts in this direction, large numbers of soil workers are still as ignorant as may be of the principles involved in the making and preservation of the material with which they work. Many of them are doing as their fathers did, because their fathers did it, just as we who ought to know better are still requiring or encouraging young men and women to study the things that their ancestors studied, because their ancestors studied them. No one can say how much more efficient our farmers would be, if they understood the principles of soil making, soil waste and soil exhaustion; but it is fair to infer that if they understood these things, the result would be so convincing that it would be better to neglect almost anything else rather than these things, in the education of those who are to gain not only their living, but the living of the larger part of mankind, from the soil.

Then there are the workers in mines of all sorts, who take from the earth beneath the soil the many things necessary for the on-going of modern life, and for the progress of commercial and industrial life in the future. This has been called the age of steel. It were better called the age of metals, for much besides steel is involved. The discovery of metals and fuels and progress in their utilization is tied up closely with the progress of geologic knowledge, and without the progress of geologic science the advances which have been made would not have been possible. It is of course true that in the final production of metals from ores chemistry has played an important part, but it is geology which has led the way in the discovery and exploitation of' the raw material, because it has discovered the principles, or some of them, involved in their origin. It is true that geologic knowledge on the part of one man may direct the development of resources where many do the actual work; but it would be interesting to know how the mining industry as a whole would be affected, if all mine-workers understood the facts and principles involved in the origin of the materials which they extract from 
the earth. How far would such knowledge go toward solving the many problems which face every mining camp, and every mining mill and smelter? How far would it go in removing labor troubles, in averting accidents, in bringing about a just distribution of profits in mining camps? To such questions specific answers are not forthcoming, but they are worthy of the most serious study, and their study may lead to a better understanding between capital and labor, and a better adjustment and an adjustment by better means, of their respective claims. Incidentally, if some of these things were better understood by those professional reformers who always take the the side of the dissatisfied, better results might be hoped for. The ignorance and therefore the incompetence of the sincerely well-disposed is one of the great obstacles to real progress.

The oil industry and all that goes with it furnishes another illustration of the importance of geologic knowledge, an importance which daily is assuming larger proportions. The rise of the cement industry is another of the great achievements of modern times in which geology has been an effective partner.

All these things concern themselves with industrial and commercial life, and what has been said may seem to place undue emphasis on material things; but I hold that these are first considerations. Men must have enough to be decent and to live decently, before their attention can be successfully directed to those things which we are pleased to call "the higher things of life." Ethics, esthetics and scientific research can hardly hope to find many effective exponents among the underfed and underclothed. In spite of what the rare individual may do, or of what the average individual may do under temporary exceptional conditions, few men, in the long run, will do much that is noble, much that contributes to progress, in the absence of something more than the mere necessities of life.

But there is quite (another aspect to geology, which does not concern itself immediately with income or with industry. The study of geology involves the contemplation of things which are enlarging and ennobling, in a spiritual sense. No education which leaves out training of the imagination is properly enlarging or ennobling; and where, outside of science, is there such opportunity for developing and training the imagination, and where in science, a better field than geology? The time-conceptions involved, the force-conceptions involved, the results involved in the operation of time and force, are among the greatest with which the student has to deal. They strengthen the mind by exercise of a sort which few other subjects afford. In space conceptions, astronomy surpasses it; in their appropriate spheres, physics and chemistry are equally effective for the educational ends here emphasized; but on the whole, no science surpasses it.

No subject affords a better field for the development of that sort of attitude of mind which seems especially to fit men for life. While there are phases of the subject which deal with facts and principles which lead to inevitable conclusions as certainly as mathematical reasoning does, there are other phases in which reasoning of another sort is called for. In most of the affairs of life, decisions are based on a preponderance of evidence. In few momentous decisions is the evidence so clear that there is but one side to the question. Rarely is the evidence $100: 0$; it is $75: 25$, or $60: 40$, or $51: 49$. And training in weighing evidence which is not overwhelmingly one-sided is one of the most important functions of education, for most of the 
important decisions of life are reached by the balancing of conflicting evidence. Thorough training in geology must lead to the balancing of seemingly conflicting evidence, for there are multitudes of questions to which the student of even the elements of the subject is introduced, concerning which evidence must be weighed, and a tentative decision reached, with a full recognition of its tentative character. The recognition of this character of a conclusion opens the way to a revision of judgment when additional facts warrant, and this attitude of mind is the attitude to which good education should lead in connection with all questions where evidence is inconclusive, and this means in connection with many of the affairs of life.

No claim is set up that no other subject does the same thing. As a matter of fact, some do and some do not; but the claim is set up that the type of' subject which works on strictly mathematical lines can not, by itself, afford the best preparations for the solution of the average problems of the average man. Neither can other types of subjects which do not involve the balancing of evidence, and the development of the power to separate what is weighty and relevant, from that which is light and irrelevant.

We progress from the uncertain to the certain. There are numerous problems in geology which were unsettled a generation ago, which have been solved now. There are many open questions now, which await solution. No subject better than geology gives training in the methods by which uncertainties are cleared up, by which stimulating but unverified hypotheses are tested, and advanced or rejected, as the case may be.

One of the great lessons which the world needs most to learn is that progress comes from cumulative achievement. If every in- dividual could be made to realize that even his tiny contribution to the sum of useful work is really moving the world along, it would add grandeur to life and dignity to all human endeavor. This is a frame of mind that should be developed in every young person, and cultivated till it becomes a habit. Where can this be done better than in connection with such a subject as geology, where the stupendous results of processes which, day by day, seem insignificant, are constantly under consideration. Nowhere else in the whole range of 'subjects in our ken is the majesty of the cumulative results of seemingly slight processes more sharply emphasized and more constantly reiterated.

Processes are at work on the land which, by themselves, would in time destroy it utterly. They have been in operation so long that they would have accomplished this result eons ago, if nature had not provided counter-activities which defeat this end. Nowhere is the inter-play of constructive and destructive forces, using these terms in their bearing on man's life and welfare, more pointedly studied.

Dr. J. M. Clarke pointed out years ago that the study of paleontology afforded the basis for much of the philosophy of modern life. Professor Chamberlain has taken the general position that the study of ancient life is the proper starting point for the study of sociology. Unquestionably these men are right, at least in the claim that some of: the principles which have been worked out laboriously in connection with modern human life, are well illustrated by the history of organisms long since extinct. It is perhaps too much to expect the sociologist to become a paleontologist first. Probably there is no more reason why he should, than why a man who wishes to use the English language well, should first become a Latin scholar. But it is 
quite possible for the sociologist to lay hold of the principles which paleontology illustrates, if paleontologists will but put them into form available for application outside the field of fossils, just as it is possible for the student of the English language to lay hold of that which is vital for his purposes in the Latin language, by short-cut methods. Analogies between the courses of events in the history of Cambrian life, and the course of human events in modern times are interesting if not instructive, and they are doubtless more numerous and more pointed than the superficial student suspects.

One of the chief functions of education is to put man into sympathetic and appreciative touch with his surroundings. His physical surroundings are an important part of his environment, always and every where, and he who does not understand, is cut off from one of the great resources of life. It is of course true that one may enjoy a landscape, even if he does not understand geology; but he will enjoy it more if he does. A man may enjoy pictures and music without understanding much about them. but he will enjoy them more if he understands. And just as some education in music and art is to be desired because it increases a man's capacity for enjoyment of the things which he sees or hears occasionally, so education with reference to the landscape, which the average man sees much more than he sees works of art, and much oftener than he hears music, is a desideratum. To go about the earth blindly, unintelligent as to the meaning of its surface configuration, is to cut off one of the great pleasures of life, and especially one of the great pleasures of travel.

Since all men are in touch with at least a limited part of the land surface, and most of them in touch with enough of it to find lasting enjoyment in it if they are taught to see what it means, is it not reasonable to conclude that the subject which teaches them to see understandingly, is one which it must be profitable to pursue? How can we justify ourselves, if we withhold this resource from this and coming generations?

Prompted by the attitude of mind which mountains inspire, I have repeatedly watched their effect on groups of students who, for the first time, live in them long enough to have their influence felt; and I have seen, or thought I saw, how littlenesses and meannesses drop away, and how the nobler qualities come to the fore. John Muir has made much of this idea in one connection and another, and I think he is entirely right. To many men. mountains are as inspiring, as uplifting, as soul-stirring, as great essays or great poems are to others. Is it not just as great a mistake to leave the one out of consideration as the other? To the average young man at least, I suspect that mountains are quite as much of an intellectual and moral tonic as the best that he finds on the printed page.

What has been said of the mountains might be said, with modifications, of other parts of the earth. If there are those who think the landscape of an unrelieved tract like that about Chicago unlovely, I think this feeling would be changed completely if the grand march of events which has made that surface what it is, were understood. While it can never have the charm to the eye that some other sort of surface has, it has its own elements of attractiveness, its own beauty, to the eye which really sees. When men belittle the attractions of the level prairie, they advertise their ignorance. One may not chose to see the flat land all the time, any more than one would choose to read poetry all the time. With equal education in the two, I am confident that the normal man could live contentedly 
with the plains longer than with poetryeven of the best.

The sea has a charm for almost every soul, but he who gets only what the eye records of color and movement, fails of the larger meaning, which, to beauty, adds grandeur. What does the salt of the sea mean? What is the period of time of its accumulation? What volumes of rockmany times all that is now above its surface-have been destroyed in its production? What range and volume of life, of which the voyager has but a glimpse, does it harbor now? What of the life of which it has been the home in the time which has passed since life was, and what of the great evolutions that have taken place within it? And what is yet to come? The great panorama of events, of processes, of changes, all of which are involved in the history of the sea, add a meaning larger than the eye, unaided, sees. To see the ocean merely as it is is like seeing the social fabric of to-day, without reference to what has been in the past, or what is to be in the future.

Our period of schooling is all too short to give us an intelligent look into all the fields with which it would be profitable to have acquaintance; but is this field on which we live and move and have our being, one we can afford to neglect?

From a wholly different point of view, geology is a valuable study. There is no subject in the curriculum which, rightly developed, can be made to lead more surely to correct methods and processes of reasoning. I remember that a former president of the Geological Society of America said, in his annual address, that the first courses in geology must be pouring-in processes, and that only later can anything be drawn out. In a sense this is of course true; but in another sense this doctrine is at the root of all that is worst in educa- tion. Geology, better than most subjects, can be taught from the beginning by the problem method. Given certain specific data-and the data may be in strict conformity to the facts of geology-the student can work out for himself the results which must follow. By this method, skillfully carried out, any man with ordinary intelligence for the comprehension of cause and effect can be let into the heart of the science with a minimum of information poured in, and that minimum bit by bit for use in the solution of problems. This method of instruction educates, but does not stuff him. The lecture method of instruction in the elements of geology, when well done, is hardly more than a stuffing process; when badly done, it is much less. In any case, it leaves the student relatively helpless in dealing independently with the reasons which give facts this meaning.

No subject within my ken lends itself better to this method of problem study than geology. In its simpler aspects, it deals with facts with which the student has some familiarity, and he can be led to reason from the known to that of which he has not thought, so that the work is, for him, original research from the outset. This is ideal education, and for this sort of education, geology is almost an ideal subject. We have heard much of discipline in education. This is the sort of discipline which counts.

There is much in the history of the science which is illustrative of the history of intellectual progress. It is not so long ago that one man's guess was about as good as another's, concerning anything that had to do with earth phenomena, and it was long years after facts began to be observed, before the convincing worth of facts was generally recognized. The history of the attitude of men toward fossils is typical of their attitude toward the science as a 
whole, and is interesting, if not instructive. Though some part of the meaning of fossils was sensed by Xenophanes in the sixth century B.c., his views were soon lost, and did not reappear until the fifteenth century, when Leonardo da Vinci reaffirmed their genuineness, combating both the idea that they were accidents in the rocks, and the idea that they were introduced for purposes of deception. It is a curious fact that it was the defenders of the faith, who by their professions might appropriately have been the most valiant defenders of the integrity of all that the Creator had made, who, to prop up certain beliefs which they feared were in danger, ascribed to the Creator ignoble motives in introducing the fossils into the rocks.

Once the integrity of fossils was accepted, the conception that they were proofs of the biblical deluge had still to be reckoned with, and it was not until recent times that paleontological knowledge became so ample that speculation as to the meaning of fossils gave place to the noble conceptions which now obtain concerning their interpretation. The history of the subject is one of the best illustrations in all the realm of knowledge, of the poteney of facts, and of the futility of generalizations without facts, and at the same time one of the best illustrations of the folly of bolstering up a lost cause by specious and ignoble arguments or affirmations.

The enlightening doctrine of organic evolution, which has perhaps done more than almost any other single doctrine to put the progress of the world on a safe track, would not have made the rapid progress it has in the last half century or so, had not the facts of geology given their powerful aid. Nowhere else can the general principles of biological evolution find more convincing support, and nowhere else can the wide application of the doctrine through long successions of ages, find unequivocal illustration. Geology therefore is one of the foundation stones of the doetrine which perhaps has done more than any other to develop the modern spirit of progress and research.

Probably no subject did more than geology to set intellectual attitudes to rights, after the baneful sway of medieval scholasticism. It became necessary in the end to deny facts or to abandon cherished beliefs, and in the long run there could be no doubt of the outcome.: There can be no doubt that the temporary denial of facts and their obvious meaning was due to the fear of their consequences on current beliefs and doctrines which rested on feeble foundations. Denial was the last resort of the attitude of mind which found itself cornered, and it ended, as this sort of defense always ends, in making the defender ridiculous.

When Section $\mathbf{E}$ was organized under the name Geology and Geography, the conception of geography was somewhat different from that of the present day. I take it that the geography of that time was akin to what is now called physical geography; and to many, physical geography still is geography. This science, especially under the name of physiography, has attained an important place in modern education, more in colleges than in schools of lower rank, chiefly because the subject is in more competent hands in the former. Physiography is the surface expression of geology, the expression of the geology of our own times. As such, it is the phase of geology which most directly appeals to many men, the phase which puts him most readily into possession of the information which gives a meaning to the landscape. It was altogether fitting that this phase of geology 
should be associated with geology in a section of this association.

But a new science of geography is growing up, almost unknown to those who are not concerned directly with its development. It is perhaps not yet very sharply defined, even to those who know it best, and hardly defined at all to others. It is clear that it is to center about the influences of earth features and earth resources on the distribution, character, and activities of life-life of all kinds. To what proportions this subject may develop, and how sharply its limits will be set, is not yet clear; but it is making giant strides where conditions for its development are favorable. It is actuated by the high motives of all science, one of which is the desire for truth for its own sake; but even more it is actuated by the desire to render its truth serviceable to mankind. Its field overlaps, in varying degrees, the fields of geology, physical geography, meteorology, botany, zoology, history, economics, and perhaps other sciences. But it uses the facts and principles of these sciences in explanation of the distribution, character and activities of life. The physical foundation for this new science of geography is geology, using that term as we should, to include all the earth, not merely the lithosphere. Whether this new science will belong properly in the same section of this association as geology, is an open question. Some phases of it do not find their closest relationships here, while others do. The subject as now conceived by those who are its leaders touches the life and welfare of the human race as intimately and as fundamentally as any other science.

There is one other aspect of both geology and geography, which gives them great educational value. Neither science is completed or nearing completion. There are great things ahead in both. As an organ- ized science, geology is older than geography, at least older than geography in its modern sense, and is the more advanced. While geology has made phenomenal advances in the last half century, the problems ahead are so numerous and so interesting that even an elementary course in the subject, properly developed, opens up great vistas for the future. I believe it to be fundamentally important that young people should be led to see visions, and be inspired by the allurements of future development. Nothing is more conducive to a right attitude toward life in general, than the feeling of the possibility of participation in the progress of the future. In this, geology is not peculiar. Only as it is less advanced than some other sciences has it the advantage over them in this respect. In saying this, I am not losing sight of the fact that but few of those who give attention to geology in their student days will ever go farther; but a comprehension of what is likely to come stimulates an abiding interest, and abiding interest in various lines of work and thought are important elements in a good education.

In modern geography the promise is perhaps even greater, since less has been accomplished. Perhaps no science touches human life and interests more closely, or in more ways. There is, I am confident, no science which, properly developed and utilized educationally, will do more for the development of good citizenship. Its substance perhaps touches the essence of material life, especially on the human side, more intimately than any other science. No other science and no other subject, unless it be sociology and possibly modem history, is likely to do so much to promote sympathetic understanding between the nations of the earth, and this is one of the greatest desiderata not only of this day and generation, but of all days and genera- 
tions. For this reason, if for no other, promulgation of the knowledge of modern geography should be furthered wherever possible.

When geography and geology, and subjects which have similar advantages, occupy larger places than they now do in our educational system, I believe that our young men and women will be better equipped than they are now to do their part in transforming a contentious world into a world of righteousness, based on mutual consideration.

\section{UnIVERSity of Chioago}

$$
\text { Rolitn D. Salisbury }
$$

\section{THE REPORT OF THE COMMITTEE TO VISIT THE HARVARD COLLEGE OBSERVATORY}

To tHE BoARd of Overseirs of Harvard CoLLEGE: The committee which you appointed to visit the astronomical observatory begs leave to submit the following report.

Both individually and as a committee we have kept in touch with the work of the observatory, visiting it from time to time and receiving statements from the director as to the condition and progress of the work.

Your committee finds the many researches going on in a most efficient and satisfactory way, and the results are published from time to time in bulletins and in the Harvard Annals which now number eighty volumes. The large amount and the high quality of the scientific output keeps the observatory in the position it has occupied for many years as one of the greatest observatories of the world.

In recent reports to you we have given in some detail the results of various special lines of investigation which the observatory has undertaken. In this report we desire to touch on the efforts of Professor Pickering to coordinate the general progress of astronomical science and to bring about a larger cooperation among the different observatories of the world.

One of the objects of the Harvard Observatory as stated in its statutes is " in general to promote the progress of knowledge in astro- nomical and kindred sciences." This, Professor Pickering has interpreted in the largest and most unselfish sense by laboring to advance the science in any and all ways, whether the particular credit for the work should come to the Harvard Observatory or not. As the object of the study was the same over-arching sky he has always believed that the most successful prosecution of the work would come from the fullest cooperation of those devoting their talents to the common aim.

Modern astronomy has demanded the most extended effort and the greatest concentration of resources extended over many years to produce the large amount of work which lies at the foundation of the astronomy of to-day. These investigations have demanded labors which no individual or institution could produce but have required the combined efforts of great observatories extending over many years.

In addition to this the best results are only obtained by division of labor and a condition where the special man and the particular problem are brought together. The science has now become so diversified that no astronomer has the versatility or the interest to carry on all the required branches of investigation. There is the problem of finance and the man; there is the problem of producing astronomical instruments as well as the man to use them; of taking photographs as well as measuring them; and, finally, the problem of estimating values and drawing reasonable conclusions from all the previous work.

In short, the progress of astronomy, like the advancement of civilization, requires many and diverse talents. It was the early realization of this truth which made Professor Pickering a pioneer in an unselfish policy to secure cooperation among astronomers so that each might be enabled to carry on the particular lines of work for which he is was best fitted. As early as 1877 he published a pamphlet on "The Endowment of Research" and advocated a closer cooperation looking to the larger interests of the science.

In 1886, a second paper was published asking for an endowment of one hundred thou- 